\title{
An audit of fatal acute pancreatitis
}

\author{
AK Banerjee, A Kaul, E Bache, AC Parberry, J Doran, ML Nicholson
}

\begin{abstract}
Summary
Acute pancreatitis has a mortality of about $10 \%$ : this figure has not changed over the last 20 years. A retrospective audit of fatal acute pancreatitis was performed in a teaching hospital with a catchment population of about 750000 patients to examine patient charactistics. Using Hospital Activity Analysis code $\mathbf{5 7 7 . 0}$, all fatal cases of acute pancreatitis were studied in a six-year period 1987-93. Additionally, all post mortem diagnoses of acute pancreatitis were traced. The overall post mortem rate in Nottingham at the time of the study was about $35 \%$. All available records, $X$-ray and biochemical data were studied and appropriate information recorded and analysed for 65 fatal cases. Only $15 \%$ were post mortem diagnoses, lower than in previous series; $72 \%$ had respiratory and $67 \%$ had renal complications. Only $34 \%$ had been admitted to the intensive care unit. A third of patients had had surgery; $67 \%$ of these was some form of external drainage. Of the 14 patients with proven gallstone pancreatitis only three had endoscopic retrograde cholangiopancreatography; $42 \%$ of patients had idiopathic disease. Not all the patients diagnosed ante mortem had the full biochemical predicted severity criteria analysed: $\mathrm{pO}_{2}$ and calcium analysis was performed in about $80 \%$. Premortem diagnoses of pancreatitis was achieved more frequently than in other comparable series.
\end{abstract}

Keywords: post mortem, acute pancreatitis, audit

Department of

Surgery, Queen's

Medical Centre,

Nottingham NG7 2UH,

UK

AK Banerjee

A Kaul

E Bache

AC Parberry

J Doran

Department of

Surgery, Leicester

General Hospital,

Leicester, UK

ML Nicholson

Correspondence to

AK Baneriee, Flat 1,

Woodbank Croft, 51

Botanical Road, Sheffield S11

8RP, UK

Accepted 29 March 1995

Acute pancreatitis remains an important clinical problem with a significant mortality and cost. ${ }^{1-4}$ Approximately $25 \%$ of all attacks of pancreatitis are severe and the average mortality rate approaches $9 \% .^{5}$ Some centres have noted an increase in the mortality rate over time ${ }^{6}$ despite apparent improvements in diagnosis and management, whereas others have noted a marked decrease. ${ }^{5}$ The most recent reviews of fatal pancreatitis relate to patients treated in Glasgow up to $1985,5,7$ in southern England $^{8}$ and in Finland ${ }^{9}$ : we therefore wished to examine whether recent advances in treatment had altered the outcome of severe acute pancreatitis. We were also able to compare our results with those of a similar audit carried out in Nottingham 20 years previously..$^{10,11}$

\section{Patients and methods}

Patients were identified from the records of the University and City Hospitals, Nottingham. All patients admitted between 1.1.87 and 31.12.93 were recruited to the study. The coding of acute pancreatitis using Hospital Activity Analysis (HAA) coding 577.0 was the only criterion for recruitment. The notes of all patients who died were studied; if the diagnosis of clinical and biochemical pancreatitis was confirmed and their death was related to pancreatitis they were entered into the study. A separate search was made for patients in whom the diagnosis of acute pancreatitis was first made at post mortem: their notes were also studied although the full biochemical and clinical criteria were often not present in this group, since the diagnosis was not clinically suspected during life.

\section{DATA RECORDED}

For each patient the age, dates of admission, operation or death was recorded. Other information included: previous admissions with pancreatitis, aetiology, clinical symptoms and signs, radiological and biochemical investigations and other tests which comprise the normal severity criteria, ${ }^{5}$ the development of either systemic or local complications, the nature of any relevant surgery or endoscopic retrograde cholangiopancreatography (ERCP) performed, admission to intensive care and postmortem findings. A proportion of patients were first diagnosed at post mortem: in this group the above investigations had often not been performed. Our overall hospital post-mortem rate was about $35 \%$, although it is possible that in severely ill patients with uncertain diagnosis the rate may have been higher.
Since the data is normally distributed, chisquared testing for parametric data was used to investigate the correlation between groups, ie, medical admissions $v s$ surgical admissions and ante-mortem vs post-mortem diagnoses. Statistics were calculated using Statgraphics program (STSC Inc, 2115 East Jefferson St, Rockville, MD 20852, USA).

\section{Results}

A total of 65 patients ( 35 male, 30 female) with fatal acute pancreatitis were seen in the Nottingham Teaching Hospitals in the period 1987-93, out of 670 patients admitted with the condition in the same period. The calculated

\section{STATISTICS}


mortality rate was therefore $9.7 \%$. Seventeen patients had previous admissions. Forty-one patients were managed under general surgeons whilst 24 had been under the physicians.

The clinical features of all the patients are displayed in table 1 . The most common symptoms were abdominal pain and vomiting and the most common signs were abdominal tenderness and distension. Pyrexia was not often seen on admission, whilst shock was a presenting feature in about a quarter of the series. A fifth were of biliary origin and $29 \%$ were of alcoholic origin, with a significantly greater proportion of the latter being admitted onto medical wards. A large proportion were idiopathic $(42 \%)$. This may reflect the case mix or suggest that idiopathic pancreatitis has a worse prognosis compared to other causes. Cardiorespiratory failure was frequently seen. Operative intervention was performed in $32 \%$ of patients and external drainage only was carried out in two-thirds of these. Operations were only rarely performed on patients initially admitted onto a medical ward. Only $34 \%$ of patients were admitted or transferred to an intensive care unit, and only $16 \%$ of patients with subsequent fatal pancreatitis under a medical team were similarly transferred. Sepsis was more commonly seen in surgical patients, whilst renal impairment was seen in nearly $70 \%$ of all patients (plasma urea $>10 \mathrm{mmol} / \mathrm{l}$ ). Ultrasound was performed in only $26 \%$ of the series: however, all 17 scans were abnormal, with either pancreatic oedema or gallstones being the most common findings. Ultrasound

Table 1 Clinical features of patients with fatal acute pancreatitis (actual patient numbers with percentage of group in brackets). Statistics by unpaired t-tests

\begin{tabular}{|c|c|c|c|c|}
\hline & Total & Medical & Surgical & Statistics \\
\hline $\begin{array}{l}\text { Patient numbers } \\
\text { Mean days as inpatient }\end{array}$ & 65 & $\begin{array}{r}24 \\
9\end{array}$ & $\begin{array}{r}41 \\
9\end{array}$ & \\
\hline \multicolumn{5}{|l|}{ Symptoms at admission } \\
\hline Pain & $56(86 \%)$ & $18(75 \%)$ & $38(93 \%)$ & ns \\
\hline Vomiting & $47(72 \%)$ & $17(71 \%)$ & $30(73 \%)$ & ns \\
\hline Fever & $5(8 \%)$ & $1(4 \%)$ & $4(10 \%)$ & ns \\
\hline Other & $31(48 \%)$ & $17(71 \%)$ & $14(34 \%)$ & $\mathrm{p}<0.01$ \\
\hline \multicolumn{5}{|l|}{ Amylase } \\
\hline Analysis performed & $58(90 \%)$ & $19(78 \%)$ & $39(95 \%)$ & $\mathrm{p}<0.01$ \\
\hline \multicolumn{5}{|l|}{ Radiological investigations } \\
\hline CXR performed & $50(77 \%)$ & $18(75 \%)$ & $32(78 \%)$ & ns \\
\hline CXR abnormal & $19(38 \%)$ & $6(33 \%)$ & $13(41 \%)$ & ns \\
\hline US performed & $17(26 \%)$ & $3(13 \%)$ & $14(34 \%)$ & ns \\
\hline US abnormal & $17(100 \%)$ & $3(100 \%)$ & $14(100 \%)$ & ns \\
\hline ERCP performed & $3(5 \%)$ & $0(0 \%)$ & $3(7 \%)$ & ns \\
\hline ERCP abnormal & $2(67 \%)$ & 0 & $2(67 \%)$ & ns \\
\hline CT performed & $4(6 \%)$ & $1(4 \%)$ & $3(7 \%)$ & ns \\
\hline CT abnormal & $4(100 \%)$ & $1(100 \%)$ & $3(100 \%)$ & ns \\
\hline \multicolumn{5}{|l|}{ Operation } \\
\hline Performed & $21(32 \%)$ & $1(4 \%)$ & $20(49 \%)$ & $\mathrm{p}<0.01$ \\
\hline Internal drain & $3(5 \%)$ & $1(4 \%)$ & $2(4 \%)$ & ns \\
\hline External drain & $14(22 \%)$ & $1(4 \%)$ & $13(32 \%)$ & $\mathrm{p}=0.02$ \\
\hline Debridement & $4\left(6_{0}^{\circ}\right)$ & $1(4 \%)$ & $3(7 \%)$ & ns \\
\hline \multicolumn{5}{|l|}{ ITU admission } \\
\hline Number & $22(34 \%)$ & $4(16 \%)$ & $18(44 \%)$ & $p=0.05$ \\
\hline
\end{tabular}

$\mathrm{CXR}=$ chest $\mathrm{X}$-ray; US = ultrasound; $\mathrm{ERCP}=$ endoscopic retrograde cholangiopancreatography; CT = computed tomography; ITU = intensive therapy unit; ns = non-significant. was less frequently used on medical compared with surgical patients. ERCP and contrast enhanced computed tomography (CT) were uncommonly used: this reflects not only the relatively low rate of gallstone pancreatitis and the fulminant nature of the condition in sick patients but also probably indicates an underutilisation of these tests. Although plasma sodium, potassium, urea and white cell count were performed on nearly all the patients in the series, calcium, arterial blood gases and liver function tests were only performed in about $70 \%$. Amylase levels were nearly always performed on surgical wards but often missed on medical admissions, although this was partly because the diagnosis was more frequently made at post mortem in the latter group.

Table 2 compares the characteristics of patients diagnosed pre- and post-mortem. Although only $15 \%$ of the total number of fatal pancreatitis were post-mortem diagnoses, a disproportionate number were from medical wards. A large number were idiopathic, even after post mortem. None of the patients undiagnosed during life had specific radiological investigation for pancreatitis, eg, ultrasound, CT scanning, or ERCP. Only three out of 10 patients in this category had an amylase estimation: all were normal and undoubtedly a normal amylase may mislead the clinician away from the correct diagnosis. However, leucocytosis and hypoxia were features in several of this group. Clinically, many of these patients presented with vomiting, abdominal pain, distension and tenderness and three were shocked on admission.

\section{Discussion}

Most clinical series cite pancreatic infection and sepsis as the principal cause of death, accounting for over $70 \%$ of fatalities. ${ }^{12,13} \mathrm{~A}$ large post-mortem study of $\mathbf{4 0 5}$ patients found, however, that $60 \%$ of deaths from acute pancreatitis occurred within the first week after admission, and pulmonary failure was more common than infection. ${ }^{14}$ These findings are similar to our own experience. ${ }^{15} \mathrm{We}$ were able to confirm the general findings that severe acute pancreatitis is often complicated by multisystem organ failure involving the cardiovascular, pulmonary and renal systems leading to a fatal outcome. Respiratory complications often

\section{Causes of death in acute panc-} reatitis

- respiratory failure, $60 \%$

- myocardial infarction/cardiac failure, $10 \%$

- renal failure, $10 \%$

- sepsis and multiple organ failure, $10 \%$

- local pancreatic causes (eg, phlegmon, necrosis, haemorrhage, bowel infarction, perforation), $10 \%$

(Approximate figures are given for the principal cause of death: there was often a secondary subsidiary cause.) 
Table 2 Comparison of cases diagnosed post-mortem vs pre-mortem. Statistics by unpaired t-tests

\begin{tabular}{|c|c|c|c|c|}
\hline & Total & Pre-mortem & Post-mortem & Statistics \\
\hline & 65 & $55\left(85_{0}^{\circ}\right)$ & $10\left(15^{\circ}{ }_{0}\right)$ & \\
\hline Medical & 24 & $18\left(75_{0}^{\circ}\right)$ & $6\left(25^{\circ}\right)$ & med $v s$ surg \\
\hline Surgical & 41 & $37\left(90_{0}^{\circ}\right)$ & $4\left(10_{0}^{\circ}\right)$ & \\
\hline \multicolumn{2}{|c|}{ Mean days as inpatient } & 10 & 4 & $\mathrm{p}<0.01$ \\
\hline \multicolumn{5}{|l|}{ Aetiology } \\
\hline Biliary & 14 & 12 & 2 & ns \\
\hline Alcohol & 19 & 19 & 0 & ns \\
\hline Other & 5 & 2 & 3 & ns \\
\hline Not known & 27 & 22 & 5 & ns \\
\hline \multicolumn{5}{|l|}{ Amylase } \\
\hline Analysis performed & 58 & $55\left(100_{0}^{\circ}\right)$ & $3\left(30_{0}^{\circ}\right)$ & $\mathrm{p}<0.01$ \\
\hline \multicolumn{5}{|c|}{ Pathological findings at post mortem } \\
\hline Analysis performed & $45\left(69_{0}^{\circ}\right)$ & $35\left(64^{\circ}{ }_{0}\right)$ & $10\left(100^{\circ}{ }_{0}\right)$ & \\
\hline Cardiovascular & $15\left(33_{0}^{\circ}\right)$ & $11\left(31_{0}^{\circ}\right)$ & $4\left(40^{\circ}{ }_{0}\right)$ & ns \\
\hline Respiratory & $28\left(62^{\circ}{ }_{0}^{\circ}\right)$ & $25\left(71_{0}^{\circ}\right)$ & $3\left(30_{0}^{\circ}\right)$ & $p=0.04$ \\
\hline Renal & $12\left(27^{\circ}{ }_{0}^{\prime}\right)$ & $11\left(31_{0}^{\circ}\right)$ & $1\left(10_{0}^{\circ}\right)$ & ns \\
\hline Pseudocyst & $3\left(7_{0}^{\circ}\right)$ & $3\left(9_{0}^{\circ}\right)$ & 0 & ns \\
\hline Phlegmon & $14\left(31_{0}^{\circ}\right)$ & $13\left(37^{\circ}{ }_{0}\right)$ & $1\left(10_{0}^{\circ}\right)$ & ns \\
\hline Perforation & $5\left(11_{0}^{\circ}\right)$ & $4\left(11_{0}^{\circ}\right)$ & $1\left(10^{\circ}{ }_{0}\right)$ & ns \\
\hline Biliary & $6\left(13_{0}^{\circ}\right)$ & $5\left(14_{0}^{0}\right)$ & $1\left(10_{0}^{\circ}\right)$ & ns \\
\hline Pancreatic oedema & $42\left(93^{\circ}\right)$ & $33\left(94_{0}^{\circ}\right)$ & $9\left(90^{\circ}{ }_{0}\right)$ & ns \\
\hline \multicolumn{5}{|l|}{ Symptoms on admission } \\
\hline Abdominal pain & $54\left(83^{\circ}{ }_{0}\right)$ & $48\left(87^{\circ}{ }_{0}\right)$ & $8\left(80^{\circ}{ }_{0}\right)$ & ns \\
\hline Vomiting & $47\left(72^{\circ}{ }_{0}\right)$ & $41\left(75^{\circ}{ }_{0}\right)$ & $6\left(60^{\circ}{ }_{0}\right)$ & ns \\
\hline Fever & $5\left(8_{0}{ }_{0}\right)$ & $3\left(5_{0}^{\circ}\right)$ & $2\left(20^{\circ}{ }_{0}\right)$ & ns \\
\hline Other & $31\left(48^{\circ}{ }_{0}\right)$ & $25\left(45^{\circ}{ }_{0}\right)$ & $6\left(60^{\circ}{ }_{0}\right)$ & ns \\
\hline \multicolumn{5}{|l|}{ Signs on admission } \\
\hline Tenderness & $57\left(88_{0}^{\circ}\right)$ & $48\left(87^{\circ}{ }_{0}\right)$ & $9\left(90_{0}^{\circ}\right)$ & ns \\
\hline Distension & $20\left(31_{0}^{\circ}\right)$ & $17\left(31_{0}^{\circ}\right)$ & $3\left(30_{0}^{\circ}\right)$ & ns \\
\hline Mass & $4\left(6^{0}{ }_{0}\right)$ & $4\left(7^{\circ}{ }_{0}\right)$ & 0 & ns \\
\hline Jaundice & $4\left(6^{\circ}\right)$ & $4\left(7_{0}^{\circ}\right)$ & 0 & ns \\
\hline Shock & $17\left(26_{0}^{\circ}\right)$ & $14\left(25^{\circ}{ }_{0}\right)$ & $3\left(30_{0}^{\circ}\right)$ & ns \\
\hline
\end{tabular}

manifested as pneumonia and adult respiratory distress syndrome, whilst renal failure commonly resulted from the severity of pancreatitis with possible inadequate fluid replacement. Sterile and infected pancreatic and peripancreatic necrotic tissue was also seen in our series of patients.

Recent evidence suggests that obesity is also a major risk factor for severe acute pancreatitis: ${ }^{16}$ in a prospective series nearly $66 \%$ of moderately or severely obese patients had severe pancreatitis, with a $36 \%$ mortality rate, as compared with only $6 \%$ of 80 non-obese patients. ${ }^{16} \mathrm{We}$ were unable to confirm this trend because accurate data on patient weights was frequently lacking. We would recommend that the weight and height of patients with acute pancreatitis should be carefully recorded and the body mass index (BMI) calculated for each patient, as this South African recommendation is the easiest quick way of grading patients in terms of obesity risk.

The Glasgow studies which reviewed all deaths from acute pancreatitis up to 1985 are among the most recent surveys and identified 126 patients, 53 of whom had pancreatitis first diagnosed at post mortem.,7 The authors pointed out that $30^{\circ} \%$ of the patients had gallstone-induced pancreatitis, $15^{\circ}$ o had alcohol as a cause and $38^{\circ}{ }_{0}$, were idiopathic. The overall mortality fell from $14.6^{\circ}{ }_{0}$ in the first half of the study to $10.8^{\circ}$ o in the latter half: within the group of 73 patients diagnosed during life, deaths from gallstone pancreatitis fell by almost $50 \%$ suggesting that improved treatment of this subgroup may have occurred. ${ }^{7}$ The case mortality rate fell in the Glasgow study from $17.8 \%$ over the period $1961-65$ to $5.6 \%$ over the period $1981-85.5$ One of the aims of the current study, therefore, was to see whether the mortality rate of the current series showed a continued trend in the reduction in mortality. Our overall mortality rate was just under $10 \%$ : in this regard therefore there had been no real improvement in Nottingham over the last 20 years. ${ }^{11,12}$ Deficiencies in in-patient statistical analysis remain.

The incidence of acute pancreatitis in the Grampian region of Scotland was investigated for the years 1983-85 by examining the record of amylase estimations carried out in the single regional laboratory performing these assays. Only $53 \%$ of the total number of cases of acute pancreatitis identified in the study had been recorded in the hospital's computer-linked diagnostic index ${ }^{17}$ : it is likely that some underreporting of non-fatal acute pancreatitis was present in our series thus resulting in an artificially high mortality rate.

Another important aspect of the study was the large number of patients with incomplete or inadequate investigations and/or management even when the diagnosis was made pre-mortem. Ultrasound of the abdomen was often not performed, and contrast-enhanced CT was rarely done. When available, these tests invariably gave valuable diagnostic and prognostic information and a greater utilisation of these investigations is one of the main areas for potential improvement. ${ }^{18,19}$ Another deficiency in clinical management was the low utilisation of intensive care beds, although it cannot be certain whether this was a clinical or resourcebased problem.

Compared to the Glasgow series a smaller number of patients were initially diagnosed at post mortem: the majority of these patients neither had appropriate radiological investigations nor a serum amylase estimation. Acute pancreatitis caused by factors other than gall-

\section{Guidelines for investigations sug-} gested for severe pancreatitis

- daily amylase, urea and electrolytes, blood gases, calcium and liver function tests

- full blood count on admission and then every 48 hours

- blood cultures if pyrexial

- hourly urine output and estimation of body mass index; other biodata to allow calculation of Apache II score

- C-reactive protein

- ultrasound scan early, to confirm diagnosis and to allow information on the presence of gallstones

- if acute cholangitis + pancreatitis then urgent ERCP + sphincterotomy

- contrast-enhanced CT scan and where available MRI 
stones or alcohol were often not diagnosed in life - this included postoperative pancreatitis where earlier diagnosis might have influenced management. We would suggest that unexplained illness and/or failure to improve in any patient at risk of pancreatitis should be accompanied by a serum amylase assay.

There is some evidence that a mortality reduction can best be achieved by reducing the number of fatal recurrent attacks of gallstone pancreatitis. This, in turn, is achievable by expedient ERCP and cholecystectomy. ${ }^{20-23}$ The number of patients in our series was not large enough to prove this plausible hypothesis.

An important overall message resulting from the study is the occasional inadequate clinical management of the patient with acute pancreatitis. Even if the condition is suspected and the diagnosis established ante mortem, the current paper shows that basic investigations were omitted or delayed and ordinary severity criteria were often overlooked..$^{22,23}$ Our findings have been confirmed by a recently published prospective audit of acute pancreatitis in the North West Thames region which recruited 631 patients in 54 months. There were 57 deaths $(9 \%)$ and $12 \%$ of this group were diagnosed post mortem. A third died within the first week, $42 \%$ had been inadequately evaluated by Ranson criteria and only $44 \%$ had undergone CT scanning. Only nine patients in

1 Carter DC. Acute pancreatitis: the value of life. Br $\mathcal{F}$ Surg 1993; 80: 1499-1500.

2 Fernandez-del Castillo C, Rattner DW, Warshaw AL. Acute pancreatitis. Lancet 1993; 342: 475-9.

3 Fenton-Lee D, Imrie CW. Pancreatic necrosis: assessmen of outcome related to quality of life and cost of management Br f Surg 1993; 80: 1579-82.

4 Doepel M, Eriksson J, Halme L, Kumpulainen T, Hockerstedt $\mathrm{K}$. Good long term results in patients surviving severe acute pancreatitis. Br $\mathcal{F}$ Surg 1993; 80: 1583-6.

5 Wilson C, Imrie CW. Changing patterns of incidence and mortality from acute pancreatitis in Scotland, 1961-1985. Br F Surg 1990; 77: 731-4.

6 Cavallani G, Riela A, Brocco G, et al. Epidemiology of acute pancreatitis. In: Beger HG, Buchler M, eds. Acute pancreatitis: research and clinical management. Berlin: SpringerVerlatis: research and clinic

7 Wilson C, Imrie CW, Carter DC. Fatal acute pancreatitis Gut 1988; 29: 782-8.

8 Mann DV, Hershman MJ, Hittinger R, Glazer G. Multicentre audit of death from acute pancreatitis. Br F Surg 1994; 81: $890-3$

9 Puolakkainen P, Valtonen V, Paananen A, Schroder T. C-Reactive protein and serum phospholipase A2 in the assessment of the severity of acute pancreatitis. Gut 1987; 28 764-71.

10 Bourke JB. Variation in annual incidence of primary acute pancreatitis in Nottingham, 1969-1974. Lancet 1975; 2 967-9.

11 Bourke JB, Giggs JA, Ebdon DS. Variations in the incidence and spatial distribution of patients with primary acute pancreatitis in Nottingham 1969-1976. Gut 1979; 20:

\section{Summary/learning points}

- pancreatitis is fatal in $10^{\circ}{ }_{0}$ of patients and the number has been constant for 20 years

- a significant number of cases are first recognised at post mortem

- respiratory failure is the commonest cause of death and the majority of these are within the first week

- falling arterial blood gas $\mathrm{pO}_{2}$ and a high body mass index are useful early predictors of severe attack

- treatment is essentially supportive

Box 3

that series had necrosectomy or surgical drainage. ${ }^{8}$

The findings in both the North West Thames series and our paper cannot be easily ascribed to a lack of facilities or funding but may instead represent a combination of ignorance and clinical complacency. One way forward is the use of clear national management protocols which should be closely followed for each admission.

AKB is in receipt of grants from Trent Regional Health Authority and the Fellowship of Postgraduate Medicine for research in acute pancreatitis.

12 Pederzoli P, Bassi C, Vesentini S, Campedelli A. A randomized multicentre clinical trial of antibiotic prophylaxis of septic complications in acute necrotizing pancreatitis with imipenem. Surg Gynecol Obstet 1993; 176: 480-3.

13 Buggy BP, Nostrant TT. Lethal pancreatitis. Am $\mathcal{f}$ Gastroenterol 1983; 78: 810-4.

14 Renner IG, Savage WT, Pantoja JL, Renner VJ. Death due to acute pancreatitis. A retrospective analysis of 405 autopsy cases. Dig Dis Sci 1985; 30: 1005-18.

15 Banerjee AK, Haggie SJ, Jones RB, Basran GS. Respiratory failure in acute pancreatitis. Postgrad Med $\mathcal{f}$ 1995; 71: 327-30.

16 Funnell IC, Bornman PC, Weakley SP, Terblanche J, Marks IN. Obesity: an important prognostic factor in acute pancreatitis. Br $\mathcal{F}$ Surg 1993; 80: 484-6.

17 Thomson SR, Hendry WS, McFarlane GA, Davidson AI. Epidemiology and outcome of acute pancreatitis. Br $\mathcal{J}$ Surg 1987; 74: 398-401.

18 Corfield AP, Cooper MJ, Williamson RCN. Acute pancreatitis: a lethal disease of increasing incidence. Gut 1985; 26: 724-9.

19 Trapnell JE, Duncan EHL. Patterns of incidence in acute pancreatitis. $B M \mathcal{F} 1975 ; 2: 179-83$.

20 Banerjee AK, Galloway SW, Kingsnorth AN. Experimenta models of acute pancreatitis. Br f Surg 1994; 81: 1096-103.

21 De Bolla AR, Obeid ML. Mortality in acute pancreatitis. Ann R Coll Surg Engl 1984; 66: 184-6.

22 Steinberg W, Tenner S. Acute pancreatitis. $N$ Engl f Med 1994; 330: 1198-210.

23 Poston GJ, Williamson RCN. Surgical management of acute pancreatitis. Br $\mathcal{F}$ Surg 1990; 77: 5-12. 